\title{
A multiplicidade de papéis e o suporte computacional às arquiteturas pedagógicas
}

\author{
Ramon Rosa Maia Vieira Junior ${ }^{1}$, Crediné Silva de Menezes ${ }^{2}$ \\ 'Pós Graduação em Informática na Educação - Universidade Federal do Rio Grande do Sul \\ Av. Paulo Gama, 110 - 90.040-060 - Porto Alegre - RS - Brasil \\ ${ }^{2}$ Faculdade de Educação - Universidade Federal do Rio Grande do Sul \\ Av. Paulo Gama, 110 - 90.046-900 - Porto Alegre - RS - Brasil \\ \{ramonwaia, credine\} @gmail.com
}

\begin{abstract}
As the rules of interaction in collaborative activities become more complex, it requires a greater demand for articulation work commitments and coordination work. The coordination, supported by computational support, can reduce conflict in group activities and foster the organization of the responsibilities of each participant. This paper investigates the cooperative activities that establish multiple roles to the same user. As a method of research, an exploratory study was performed to identify the functional requirements of software, through the behavioral models of architectures Pedagogical Debate Thesis and Academic Controversy. As a result, we present a proposal for structural modeling able to support of the multiplicity of profiles, based on the requirements identified in Architectures Pedagogical evaluated. .
\end{abstract}

Resumo. À medida que as regras de interação, em atividades colaborativas, tornam-se mais complexas, exige-se uma demanda maior de trabalho de articulação dos compromissos e coordenação das tarefas dos participantes. Os mecanismos explícitos de coordenação, apoiado pelo suporte computacional, podem reduzir os conflitos operacionais nos trabalhos em grupo e favorecer a organização das responsabilidades de cada colaborador. Destaca-se neste trabalho, as atividades cooperativas, apoiada por propostas pedagógicas, que estabelecem múltiplos papéis a um mesmo colaborador. Como método de pesquisa, realiza-se uma pesquisa exploratória para identificar os requisitos funcionais de software, através dos modelos comportamentais das Arquiteturas Pedagógicas Debate de Teses e Controvérsia Acadêmica. Como resultado, apresenta-se uma proposta de modelagem estrutural capaz de satisfazer o suporte à multiplicidade de papéis, baseada nos requisitos identificados nas Arquiteturas Pedagógicas analisadas.

\section{Introdução}

As ferramentas de autorias colaborativas disponíveis no ciberespaço ampliam as oportunidades de cooperação e favorecem o suporte a novas propostas pedagógicas em favor da aprendizagem. Diversas arquiteturas pedagógicas foram propostas com regras de interação bem definidas, conforme apresentado por Nevado et al. (2007). À medida que as regras de interação, em atividades colaborativas, tornam-se mais complexas, exige-se uma demanda maior de trabalho de articulação dos compromissos e coordenação das tarefas dos participantes. Os groupwares em consonância com esta exigência, devem auxiliar o mediador a coordenar o trabalho colaborativo.

Ao considerar a grande oferta de sistemas colaborativos virtuais disponíveis, levantam-se algumas questões que são atribuídas como motivação deste trabalho: no que se refere à coordenação das atribuições dos compromissos (tarefas de escrita e leitura) de cada perfil participante, originada por cada proposta pedagógica, quais groupwares estariam aptos para apoiar 
a realização, respeitando a multiplicidade de papéis, das Arquiteturas Pedagógicas (APs)?

Estes questionamentos levam-nos a discutir acerca dos limites dos atuais sistemas colaborativos em apoiar atividades colaborativas, onde possuem regras de interação mais complexas, principalmente pela reconfiguração em tempo de execução da colaboração. Através da avaliação realizada por Vieira Junior et al. (2011), verificou-se a necessidade de Ambientes Virtuais de Aprendizagens mais aderentes aos requisitos críticos que favorecem a realização das APs, com maior articulação e coordenação das atividades coletivas. Definido por Vieira Junior et al. (2011), este trabalho destaca um dos requisitos de softwares, para apoiar a gestão de múltiplas responsabilidades a um mesmo colaborador, denominado como multiplicidade de papéis.

Como método de pesquisa deste trabalho realizou-se uma pesquisa exploratória, utilizando as Arquiteturas Pedagógicas Debate de Teses [Nevado et al. 2011] e Controvérsia Acadêmica [Johnson e Johnson 1996] em uma investigação para identificar os principais requisitos de software, capazes de apoiar a multiplicidade de papéis em atividades em grupo. A escolha das APs foi baseada nos critérios: utilização da troca de mensagem como principal forma de comunicação e cooperação; agrupamento de participantes em perfis de atuação; e a definição de regras específicas de interação, que requeira que um mesmo sujeito participe das atividades em grupo em mais de um perfil de colaborador. A partir da descrição de cada AP selecionada, elabora-se um modelo comportamental e investigamos os requisitos necessários para elaborar uma solução computacional que apoie a multiplicidade de papéis. De posse dos requisitos, este trabalho apresenta uma proposta de um modelo estrutural de solução em software, capaz de apoiar a multiplicidade de papéis no desenvolvimento de novos em groupwares flexíveis.

\section{Referencial Teórico e Trabalhos Relacionados}

Mesmo considerando a grande oferta de ambientes CSCW/ CSCL - (Computer Supported Cooperative Work / Computer Supported Collaborative Learning), constatamos ainda um esforço de desenvolvimento de novas soluções em softwares para atender a demanda de novas propostas pedagógicas. A fim de limitar o escopo da nossa pesquisa, considera-se neste trabalho, as propostas pedagógicas e o suporte dos groupwares que utilizam textos e hipertextos como principal artefato de comunicação e cooperação. Utilizamos a definição de groupwares, por Ellis et al. (1991), como sistemas baseado em computador que suporta grupos de pessoas comprometidas em uma tarefa (objetivo) comum e fornece uma interface para um ambiente compartilhado.

Através da avaliação realizada por Vieira Junior et al. (2011), verificou-se a inadequação do suporte computacional, oferecidos por um conjunto de groupwares - reconhecidos como Learning Management Systems (LMS) ou Ambientes Virtuais de Aprendizagens (AVAs). A avaliação destaca à falta de alinhamento entre as propostas de interação das arquiteturas pedagógicas e o suporte computacional, devido à falta de flexibilidade, tanto na articulação, quanto na coordenação das atividades colaborativas, e a complexidade mediante a variação de cenários das propostas de cooperação. Como resultado, Vieira Junior et al. (2011) conclui que há necessidades de adequações das atividades propostas pelas APs aos AVAs.

As dificuldades na implementação/realização de propostas pedagógicas também são evidenciadas por: Fagundes et al. (2006) em sua proposta de Projetos de Aprendizagem e a necessidade de conceber uma solução específica de software; Menezes et al. (2008) através das evidências das inadequações dos ambientes virtuais pela falta de flexibilidade no apoio à aprendizagem cooperativa; Vieira Junior et al. (2011) ao realizar a avaliação de AVAs na implementação de APs; e Santos et al. (2010) em sua proposta de framework para descrever novas ferramentas de apoio as APs.

Esse trabalho considera a flexibilidade dos groupwares como: a capacidade de prover parâmetros de configuração e reconfiguração (em tempo de execução) no atendimento a requisitos dinâmicos, através das "4 Collaboration concern layers", conforme proposto por Farias et al. (2005). As camadas são compostas pelas seguintes preocupações de acesso: Recurso, Colaboração, Usuário e Interface. As camadas representam respectivamente: acesso ao compartilhamento de informação, os diferentes aspectos lógicos de colaboração, as atividades de um usuário dentro do processo de colaboração e a interação entre o usuário e os componentes do groupware. 


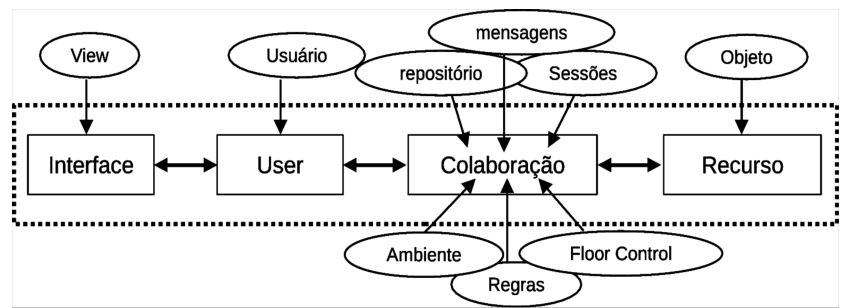

Figura 1. Relação das 4 camadas proposto por Farias et al. (2005) com os 9 conceitos proposto por Guerrero e Fuller (2001)

Sintetizado por Ochoa et al. (2004), Guerrero e Fuller (2001) define 9 conceitos básicos, eventualmente presentes em groupwares. Estes conceitos são: sessões, usuários, regras, mensagens, objetos, repositórios, views (filtro/visualização), ambiente e floor control (política para gerenciamento de recursos compartilhados). Percebemos que os conceitos básicos Guerrero e Fuller (2001) e a proposta das camadas de colaboração [Farias et al. 2005] estão sob uma mesma perspectiva, conforme apresentado na Figura 1. Complementando, Fuks et al. (2007) estabelece um modelo para colaboração - Modelo 3C. O modelo destaca a relação das atividades de comunicação, coordenação e comunicação em um processo cíclico e contínuo. Neste trabalho adota-se os conceitos do Modelo 3C e, portanto, define-se como atividade de coordenação as atribuições de perfis e designações de papéis em uma proposta de colaboração.

\subsection{Aprendizagem Colaborativa}

A aprendizagem colaborativa requer um ambiente diferente do tradicional, já que professores e alunos desempenham novos papéis. Os alunos são ativos e responsáveis por sua própria aprendizagem. O professor deixa de ser o centro das atenções e o detentor do conhecimento, e passar a promover propostas pedagógicas para que os alunos possam progredir por seus próprios esforços Castro e Menezes (2012). Nesta perspectiva, as arquiteturas pedagógicas são definidas por Nevado et al. (2007) como "suportes estruturantes" para a aprendizagem, que combinam o aparato técnico com a visão pedagógica, numa ideia ecossistêmica. Essa combinação inclui elementos como: abordagem pedagógica, software, internet, Educação a Distância, concepção de interconexão em tempos e espaços múltiplos. Seguindo esta proposta, em promoção da aprendizagem, possuímos na literatura diversas APs, algumas são abordadas em Nevado et al. (2007). Neste trabalho destacam-se: o Debate de Teses [Nevado et al. 2011] e a Controvérsia Acadêmica [Johnson e Johnson 1996]. Ambas as arquiteturas são apresentadas na seção 4.1 e 4.2, respectivamente.

\subsection{A inadequação na gerência de papéis}

Em Menezes et al. (2008), Nevado et al. (2007) e Santos et al. (2010) são apresentadas evidências sobre à ausência de softwares adequados para apoiar a realização de APs. Vieira Junior et al. (2011) conclui que independentemente da oferta atual de groupwares disponíveis para utilização, ainda é necessário uma grande adaptação das propostas pedagógicas aos softwares, e não o contrário como esperado. A necessidade constante de desenvolvimento de novos groupwares para atender propostas pedagógicas - que apoiam regras de cooperação através de tarefas de leitura e escrita de hipertextos em espaços compartilhados - atesta a falta de flexibilidade nas configurações dos protocolos de interações. Vieira Junior et al. (2011) apresenta o requisito de software multiplicidade de papéis, dentre outros, como uma das preocupações que os groupwares devem considerar em suas arquiteturas de softwares, afim de avançar sob estes aspectos.

É comum em sistemas, que apoiam as atividades colaborativas, o agrupamento de responsabilidades a um perfil de usuário. Portanto, um conjunto de regras, permissões e restrições podem ser atribuídas a um codinome (perfil), para posteriormente ser atribuído (papel) a um usuário. Evita-se assim, atribuições repetitivas de um mesmo conjunto de responsabilidades para vários usuários do sistema, o que facilita a coordenação dos usuários e suas atividades.

Quando um sistema apresenta papéis bem definidos, os conjuntos de atividades que estes desempenham são também pré-definidos. A predefinição de papéis e atividades impõe limitações às alterações das permissões dos participantes em propostas de atividades específicas. Em outros 
sistemas, como editores colaborativos (wikis), as tarefas de escrita e leituras são muito permissivas e a gestão das atividades, no que refere-se ao controle de responsabilidades, é dificultada. Neste cenário, potencializa o risco de uma sobrecarga de atividades de coordenação devido aos possíveis conflitos na cooperação. Uma vez que, as atividades de permissão, de leitura e escrita, não são gerenciadas pelo software, os colaboradores possuem a liberdade de executá-las livremente. A falta de mecanismos de controle de permissão dos usuários e do gerenciamento de recursos compartilhados podem comprometer os compromissos acordados, além de resultar em retrabalho e perda de artefatos produzidos. Como evidência dos problemas discutidos, Schmitt (2006) relata as dificuldades encontradas com o uso de editores colaborativos (Wiki) permissivos.

\section{Planejamento das atividades colaborativas e Multiplicidade de Papéis}

Antes da colaboração iniciar ocorre uma fase de planejamento - a articulação. Esta consiste em todas as tarefas envolvidas na preparação do ambiente, agendamento, monitoramento e coordenação de todas as etapas necessárias para completar as atividades [Schmidt e Bannon 1992]. Considera-se como fase do processo de articulação atividades como: identificação dos objetivos, o mapeamento destes objetivos em tarefas, a seleção dos participantes e a delegação das tarefas. Para que as atividades cooperativas ocorram de acordo com um determinado protocolo de interação é necessário que ocorra uma articulação entre os elementos (atores, artefatos, tarefas e ambiente) da atividade.

Nos ambientes baseados em cooperação por texto, onde a comunicação pode ser realizada de forma síncrona ou assíncrona, algumas permissões e restrições são gerenciadas, como: acesso aos artefatos, acesso aos espaços compartilhados, controle de acesso e prazos para edição (escrita) e controle de acesso e prazos para visualização (leitura). A cargo de um articulador da colaboração, a associação de tarefas aos colaboradores também faz parte da atribuição de responsabilidades.

APs apresentadas em Castro e Menezes (2012) e Nevado et al. (2007) estabelecem uma dinâmica de grupo a serem realizadas, através de um suporte computacional, com restrições e permissões (regras) bem definidas, protocolos de interações (floor control) que envolve a produção e o compartilhamento (repositório) de artefatos (objeto). Destaca-se a Controvérsia Acadêmica e o Debate de Teses pelas mudanças de papéis durante a realização das atividades. Deste modo, ocorre a associação entre participante (usuário) e atividades são alteradas em um determinado momento (sessão) da dinâmica. O suporte computacional deve gerir as permissões, a fim de satisfazer as atividades de coordenação e garantir que um conjunto de usuários possa atuar em mais de um perfil em um mesmo espaço, ou diferentes, sem a perda dos registros individuais e coletivos.

O requisito de coordenação nomeado como Multiplicidade de Papéis possui a responsabilidade de descrever o suporte à delegação de mais de um perfil a um mesmo usuário, dentro de um mesmo espaço coletivo, em uma proposta de colaboração.

\section{Avaliação das Arquiteturas Pedagógicas}

A partir da descrição de cada AP selecionada, instancia-se uma proposta de interação, representada através de um modelo comportamental (UML) para uma interação assíncrona. Desta forma, investiga-se os requisitos necessários para elaborar uma solução computacional que apoie a multiplicidade de papéis.

\subsection{Debate de Teses}

A descrição da dinâmica do debate de teses segue a proposta de Nevado et al. (2011). Consideram-se os perfis dos participantes, o fluxo de debate (pré e pós-condições), as restrições e permissões de cada perfil. No ambiente do mediador (moderador) são realizadas as seguintes atividades: inclusão de participantes, criação/edição de cronograma para o debate, cadastramento de teses, definição de revisores e intervenções (comunicação). As intervenções são realizadas através de mensagens privadas nas atividades de cooperação dos argumentadores e revisores.

No ambiente dos argumentadores, cada um é convidado a fazer uma apresentação inicial (etapa 1) onde deve-se elaborar um texto sobre a sua visão a priori sobre o tema em debate. Durante as interações cada indivíduo, assume dois papéis, um de argumentador e outro de revisor. As 
permissões de acesso aos espaços, para leitura ou edição são habilitadas de acordo com o cronograma, editado pelo mediador. Na etapa de argumentação (etapa 2) o participante só tem acesso à sua página de argumentação, com a possibilidade de edição do argumento. Após esta fase, a permissão para edição é desabilitada com a finalidade de evitar conflitos (alterações fora do período) na etapa de revisão . Na fase de revisão (etapa 3) cada participante argumentador possui acesso às páginas de argumentação de seus revisandos, assumindo um papel de revisor, onde possuirá permissão de leitura dos argumentos dos outros participantes (escolhidos pelo mediador) e permissão de escrita para a edição de sua revisão. A leitura do parecer dos demais revisores não é permitida nesta etapa. Na etapa de réplica (etapa 4), o argumentador apresenta as suas considerações (contra-argumentação) a cada parecer de seus revisores, os revisores têm acesso, tanto ao seu parecer e réplica (como revisor), quanto à revisão realizada por outro revisor do seu argumento. A penúltima etapa é a de re-argumentação (etapa 5), quando cada participante é convidado a criar uma nova versão de sua argumentação com seu posicionamento final. Ao final, ele é convidado (etapa 6) a fazer um texto sintetizador sobre todos os acontecimentos, inclusive sobre o seu processo de construção de conhecimento sobre o assunto debatido.

\subsubsection{Análise}

A rede de interações do Debate de Teses revela os seguintes perfis: Argumentador, Revisor e Mediador. O workflow de interação pode ser visualizado na Figura 2. O mediador, (articulador) que possui a responsabilidade de articular o processo de colaboração, inicia o debate e delega os usuários aos seus respectivos perfis. O mediador, recorrentemente representado pelo professor, poderá realizar comentários privados sobre as postagens realizadas pelos demais colaboradores.

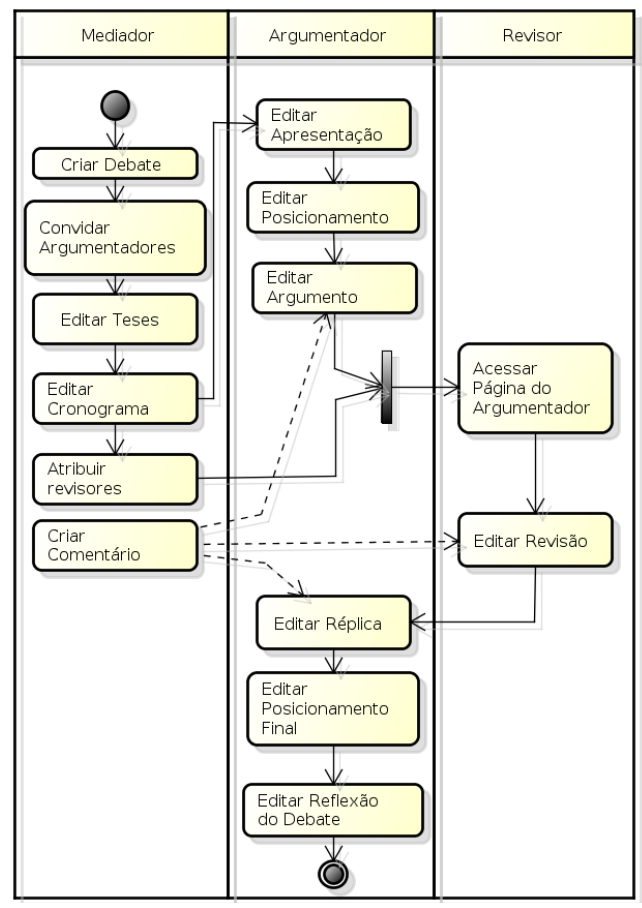

Figura 2. Atividades da AP Debate de Teses

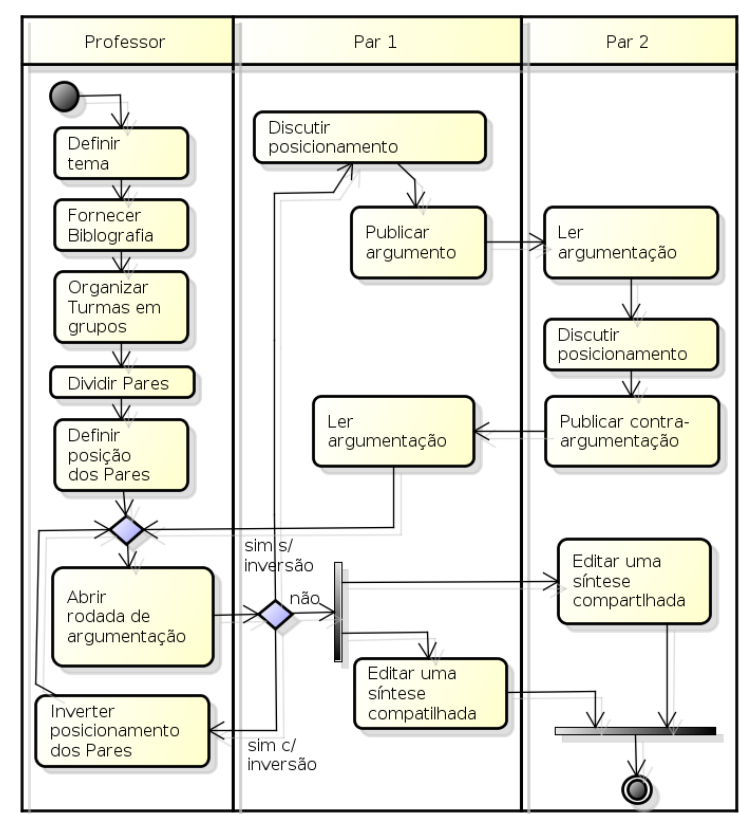

Figura 3. Atividades da AP Controvérsia Acadêmica

A descrição do Debate de Teses permite evidenciar que o mediador deve decidir quem, e quando, deve realizar determinadas ações no debate. A multiplicidade de papéis é oriunda através dos perfis de Argumentador e Revisor. Segundo a proposta pedagógica, um ator (Aluno A) pode assumir ambos os perfis em um mesmo grupo de debate, ao mesmo tempo a partir da delegação do mediador.

Percebemos que este acúmulo de papéis ocorre a partir da "etapa 2". Em cada papel, o ator responde por um conjunto de permissões e restrições de escrita e leitura (acesso). Na revisão por pares, um revisor não deve possuir permissão de leitura de uma revisão realizada pelo outro revisor, mesmo pertencendo a um mesmo subgrupo, conforme a divisão ilustrada na Figura 4. Este aspecto 
amplia a complexidade da gestão de permissões por parte do suporte computacional, uma vez que dois atores, sob um mesmo perfil, possui restrições de visualização, perante o outro, em um mesmo espaço compartilhado.

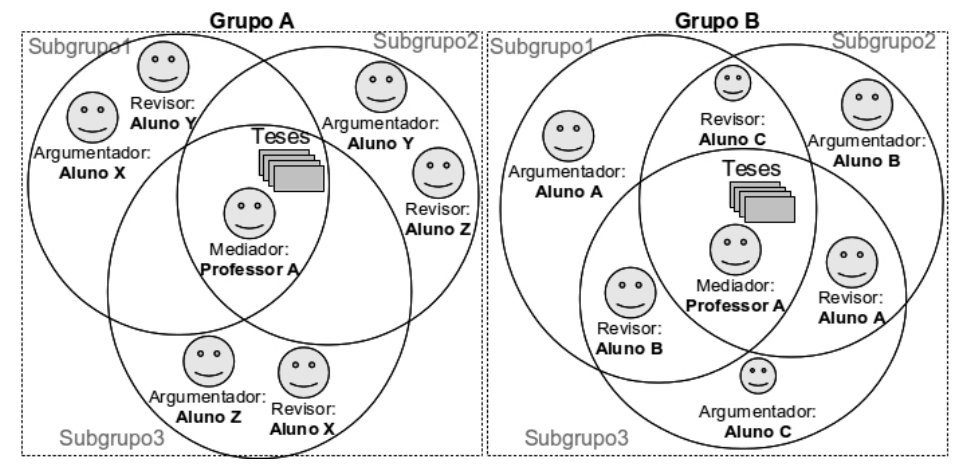

Figura 4. Representação de múltiplos papéis na AP Debate de Teses

Nesta análise, identificamos algumas características importantes para o suporte da multiplicidade de papéis:

- Um ator pode assumir mais de um perfil em um mesmo grupo:

i) em espaços compartilhados diferentes;

ii) em um mesmo período ou períodos distintos;

iii) com permissões e restrições distintas ao mesmo perfil e no mesmo espaço;

iv) em subgrupos diferentes;

\subsection{Controvérsia Acadêmica}

A controvérsia acadêmica busca chegar a um consenso quanto à discordância entre os estudantes sobre uma ideia, informação, conclusão, teoria e opinião [Johnson e Johnson 1996]. Os conflitos intelectuais são inevitáveis e atualmente desejáveis, pois contribuem para que a aprendizagem colaborativa promova um nível mais elaborado de raciocínio, maior retenção e maior criatividade do que a aprendizagem competitiva individualista. Algumas circunstâncias são necessárias para que a controvérsia acadêmica resulte em benefícios, dentre elas: contexto colaborativo; heterogeneidade entre participantes; distribuição de informações relevantes; e habilidade sociais para o conflito e argumentação racional Castro e Menezes (2012).

Conforme a descrito em Castro e Menezes (2012), a controvérsia acadêmica possui uma sequência de atividade em grupos, organizadas em cinco etapas:

1. Organização: A organização da turma em grupos de quatro estudantes, posteriormente dividido em dois pares. Cada par pesquisa sobre uma posição designada, organiza suas descobertas em um arcabouço conceitual, buscando construir argumentos persuasivos e convincentes para validar a sua posição.

2. Argumentação: Os estudantes apresentam persuasivamente o melhor argumento possível para a sua posição, ouvem cuidadosamente a apresentação oposta, e tentam aprender os dados e a lógica sobre os quais eles se basearam.

3. Contra-argumentação: Os estudantes se engajam em uma discussão aberta, continuam a advogar suas posições enquanto tentam aprender sobre a posição oposta. Analisam criticamente as evidências e lógica da posição contrária e tentam refutá-las. Ao mesmo tempo, fazem réplica às críticas que recebem sobre as evidências e lógica que apresentam na tentativa de persuadir a outra dupla.

4. Inversão de Perspectiva: Os estudantes invertem as perspectivas e passam a advogar a posição oposta tão sincera, completa, precisa e persuasivamente quanto possível. Para liberar os estudantes de suas antigas convicções, os mesmos devem insistir em pesquisa, recorrer as anotações feitas durante os passos 2 e 3 , desenvolver um arcabouço conceitual contendo os melhores argumentos possíveis para validar a nova posição e persuadir a outra dupla. 


\section{CBIE-LACLO 2015}

Anais do XXVI Simpósio Brasileiro de Informática na Educação (SBIE 2015)

5. Síntese: Os estudantes voltam à composição inicial do grupo, com 4 integrantes e desenvolvem uma síntese que integra as diferentes ideias e fatos em uma única posição. Os estudantes consideram as melhores evidências e raciocínio de ambos os lados. O propósito dual da síntese é chegar a melhor posição sobre o assunto e encontrar argumentos que todos os membros do grupo possam concordar e se comprometer.

\subsubsection{Análise}

A proposta original da "Controvérsia Acadêmica" foi idealizada em uma cooperação onde o processo de interação (comunicação) fosse, em sua grande parte, síncrono e presencial. No modelo comportamental, apresentado na Figura 3, foram realizadas algumas adaptações para uma proposta de cooperação assíncrona, apoiada por suporte computacional.

As adaptações foram, basicamente, estabelecer as pré-condições, através do sequenciamento de atividades realizadas pelos pares. Atribuir ao perfil do professor, a coordenação das rodadas de argumentações e contra-argumentação, realizadas pelos pares. O número de rodadas de argumentação é indefinido. O professor encerra este ciclo em duas ocasiões: para a inversão de posicionamento (ocorre duas vezes - inverter e reverter) ou quando inicia a quinta etapa.

Comparada ao debate de teses, a divisão de perfis da controvérsia acadêmica é mais simplificada. O grupo é subdividido em dois pares. Identifica-se que os atores, de um mesmo subgrupo, possuem as mesmas responsabilidades entre si. Ambos os subgrupos possuem acesso a artefatos compartilhados pelo mediador, como os materiais bibliográficos iniciais e o documento de síntese final. Estas atribuições podem ser feitas aos subgrupos separadamente, ou ao grupo total inicial, pois não haveria impacto negativo devido à baixa quantidade de restrições.

Diferentemente do debate de teses, a alternância de compromissos de cooperação não é imposta de forma explícita. Na "etapa 4" o mediador realiza a inversão dos posicionamentos iniciais, quando atribui a posição dos pares. O que se exige dos pares é apenas uma alteração conceitual nas atividades de cooperação, isto é, o ator continua executando a mesma atividade, mas o conteúdo deve ser alterado pela nova postura proposta pelo Professor. de papéis:

Nesta análise, identificamos algumas outras características para o suporte da multiplicidade

- Um ator pode assumir mais de um perfil em um mesmo grupo:

i) em um mesmo espaço;

ii) em períodos de tempos diferentes;

iii) com permissões e restrições iguais ao mesmo perfil e no mesmo espaço;

\section{Resultados}

A partir da análise das Arquiteturas Pedagógicas Debate de Teses e Controvérsia Acadêmica, identificam-se alguns requisitos que permite aproximar para um melhor suporte à multiplicidade de papéis. Dentre os aspectos da colaboração, percebe-se o tempo e espaço estão fortemente relacionados às regras de cooperação. As APs analisadas se utilizam da multiplicidade para gerar "conflitos" e "desequilíbrios" em favor da aprendizagem, conforme a teoria piagetiana em suas estratégias construtivistas. No entanto, estas regras de interação demandam requisitos de softwares específicos, com os identificados:

- Um ator pode assumir mais de um perfil em um mesmo grupo:

i) em um mesmo espaço compartilhado, ou diferente;

ii) em um mesmo período ou diferentes;

iii) com permissões e restrições distintas, ou iguais, ao mesmo perfil e no mesmo espaço;

iv) em subgrupos diferentes;

\subsection{Solução}

De posse da descrição dos requisitos que acercam a multiplicidade de papéis, este trabalho apresenta uma proposta de um modelo estrutural de solução em software, capaz de apoiar a 


\section{CBIE-LACLO 2015}

Anais do XXVI Simpósio Brasileiro de Informática na Educação (SBIE 2015)

multiplicidade de papéis no desenvolvimento de novos em groupwares flexíveis. A solução proposta é oriunda dos fundamentos teóricos que embasam o projeto MOrFEu - Multi-Organizador Flexível de Espaços virtUais - descrito em Menezes et al. (2008). Seguindo a mesma perspectiva teórica, Santos et al. (2010) apresenta uma proposta de descrição de ferramentas de autoria para apoiar a realização de APs, no entanto não apresenta as mesmas preocupações levantadas neste trabalho, principalmente no que tange ao suporte de multiplicidade de papéis.

Na Figura 5 é apresentado um trecho do modelo estrutural - diagrama de classe - com elementos responsáveis pela organização do espaço colaborativo, organização dinâmica das atividades cooperativas, suporte à autoria e pela gerência das regras de negócio, com ênfase no apoio a multiplicidade de papéis. O elemento principal da solução proposta é o Veículo de Comunicação (VCom), responsável pela concepção de um espaço virtual colaborativo. O espaço colaborativo deve ser organizado em múltiplas divisões para atender os espaços reservados de possíveis subgrupos ou de artefatos. A seção é uma classe de elementos que possui a responsabilidade de compor um VCom com subdivisões lógicas. Ou seja, a seção possui a capacidade de permitir a criação de categorias, divisão, agrupamento de espaços (subespaços do VCom) virtuais. Nas propostas de Menezes et al. (2008) e Santos et al. (2010), um VCom pode possuir $n$ (vários) VComs, como forma também de organização do espaço. Na proposta deste trabalho, a responsabilidade de criar divisões em espaços internos é delegada à Seção, permitindo nesta classe a capacidade de elaborar uma organização em uma estrutura de dados do tipo árvore.

Para atender a flexibilidade nas construções das atividades de cooperação, as atividades são articuladas previamente. Geralmente as produções de artefatos e/ou autorias são realizadas durante a execução (realização) das atividades, entretanto a organização das produções pode estar sujeita à dependência de outras produções (autorias), como uma réplica ou um comentário já efetuado. Por este motivo, o modelo estabelece o elemento Etapa, para viabilizar a estrutura de relações entre as produções.

Cada Unidade de Produção Intelectual (UPI) produzida em um VCom é considerada uma postagem, que será manipulada e registrada pela classe de objeto Post. Uma instância de Post é um objeto que representa um artefato gerado pelo processo de socialização das produções no VCom. Cada Post é necessariamente o resultado da execução de uma Etapa, realizada através de uma atividade de Postagem. Entretanto não é o Post o responsável pelo conteúdo das autorias, mas sim o elemento UPI. Uma Etapa resultará em um Post, ou em uma coleção de Posts, que por sua vez estará contido em um Container de Postagens. Uma Etapa pode possuir um relacionamento de dependência com outra Etapa, assim determina-se o seu autorrelacionamento.

Para satisfazer a flexibilidade no ambiente MOrFEu na articulação do trabalho colaborativo destaca-se a relação dos três elementos - Usuário, Perfil e Papel. Cada elemento está representado por sua respectiva classe de objetos. Usuário é um participante (colaborador) presente no ambiente. Perfil é um apelido para representar um conjunto de responsabilidades, tendo como exemplo: mediador, aluno, revisor, entre outros. Papel é associação entre um usuário e um Perfil, isto é, delegar o Usuário X ao Perfil Y. Assim, o Perfil, que poderá possuir um conjunto de permissões, associará a um usuário quando um Papel for criado. 


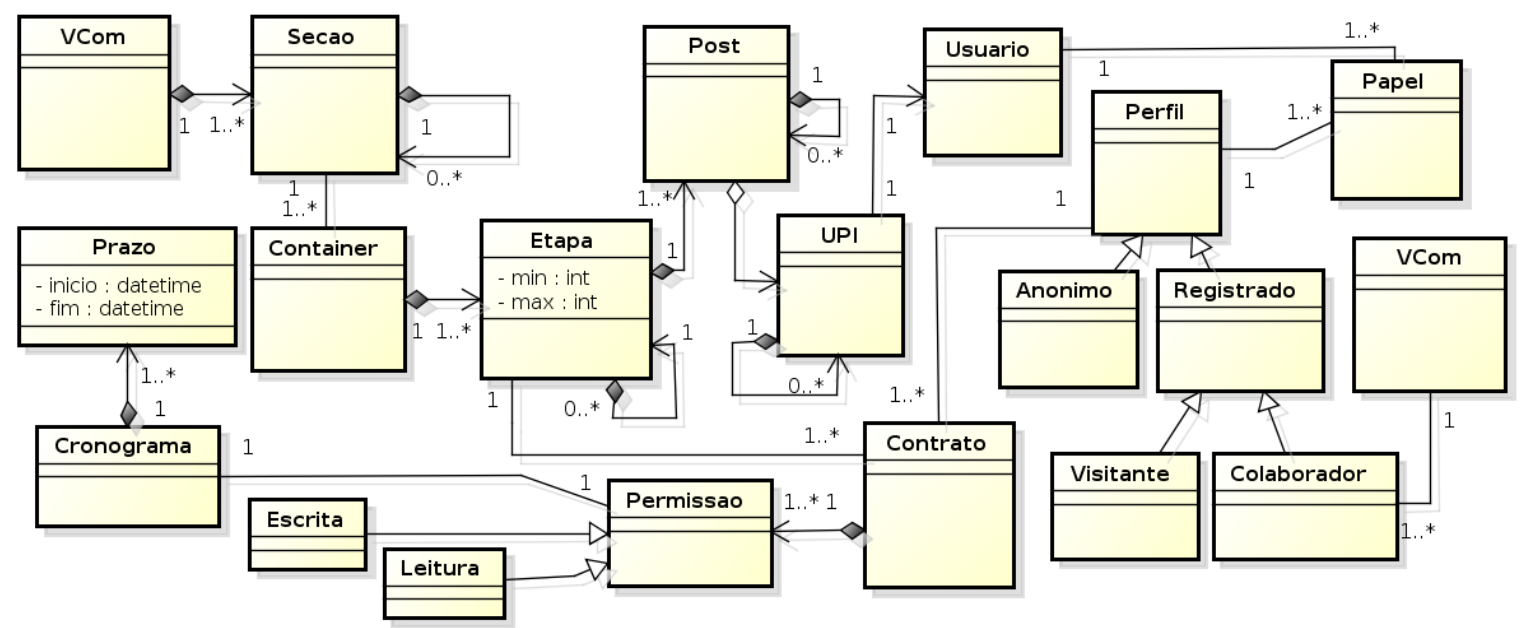

Figura 5. Diagrama de Classe

Através da Classe Contrato é possível: (i) Associar os Perfis de Usuário às Etapas; (ii) Determinar um conjunto de permissões de leitura (acesso) e escrita (criação e edição); (iii) Determinar, através das permissões, as restrições temporais tornando explícito os prazos iniciais e finais. A coleção destes prazos constitui um cronograma que estará associado à determinada permissão. Enquanto a atribuição de papel estabelece uma das atividades da fase de articulação, a configuração do contrato possibilita um maior controle tanto na fase de articulação, quanto na fase de coordenação da colaboração.

\section{Conclusões}

Apesar da variedade de groupwares para apoiar a comunicação e cooperação em espaços virtuais colaborativos, os seus mecanismos de coordenação ainda possuem limitações, referente as adaptações às necessidades de cooperação das APs. Este trabalho teve por objetivo abordar a problemática do suporte computacional, dos sistemas colaborativos, às atividades dinâmicas, propostas pelas APs, que estabelecem dinamicamente a atribuição de múltiplos papéis aos seus participantes, pertencente a um mesmo grupo de trabalho.

O requisito de software, chamado multiplicidade de papéis, exige uma flexibilidade dos ambientes colaborativos ao suporte de novas associações de restrições/permissões/obrigações aos colaboradores. $\mathrm{O}$ atendimento deste requisito ainda é limitado nos ambientes atuais, pois possuem uma configuração de permissões limitadas, onde as atividades e suas relações são estáticas ou pré-definidas previamente pelas suas respectivas arquiteturas de softwares.

A partir das análises das APs Controvérsia Acadêmica e Debate de Teses, este trabalho apresentou uma solução que estabelece uma complementação às soluções propostas por Menezes $e t$ al. (2008) e Santos et al. (2010) a fim de reduzir os problemas apontados por Vieira Junior et al. (2011), e aproximar as novas soluções em groupwares às Arquiteturas Pedagógicas, que utilizam textos e hipertextos como principal artefato de comunicação e cooperação, em favor da flexibilidade nas configurações dos protocolos de interações e floor control.

O Modelo de classe proposto apresenta uma solução, no qual os elementos são estruturados para atender a variação das regras de negócios em atividades colaborativas, em destaque ao requisito supracitado neste trabalho, nomeado como "multiplicidade de papéis". A relação entre as classes de objetos Usuário x Papel x Perfil, destaca a formação de grupos e subgrupos de usuários. O elemento Contrato permite que Perfis sejam associados a um cronograma de permissões (escrita e leitura) em uma Etapa específica. Desta forma, um Perfil (aluno, professor, mediador, revisor...) poderá possuir um conjunto de permissões para cada Etapa criada em um espaço virtual (VCom x Seções), e portanto configura-se seus papéis e respeita-se suas responsabilidades no grupo. 


\section{Referências}

Castro, A. and Menezes, C. (2012). Aprendizagem colaborativa com suporte computacional. In Pimentel, M. and Fuks, H., editors, Sistemas Colaborativos , p. 135 - 153. Elsevier Editora Ltda.

De Farias, C. R. G., Gonc, alves, C. E., Rosatelli, M. C., Pires, L. F., and van Sinderen, M. (2005). An architectural model for component groupware. In Proceedings of the 11th International Conference on Groupware, CRIWG'05, p. 105-120, Berlin, Heidelberg. Springer-Verlag.

Ellis, C. A., Gibbs, S. J., and Rein, G. (1991). Groupware: Some issues and experiences. Commun. ACM , 34(1). p. 39-58.

Fagundes, L. d. C., Nevado, R. A. d., Basso, M. V., Bitencourt, J., Menezes, C. S. d., Monteiro, V. C. P. (2006). Projetos de aprendizagem-uma experiência mediada por ambientes telemáticos. Revista brasileira de Informática na Educação , 14(1).

Fuks, H., Raposo, A., Gerosa, M. A., Pimentel, M., and Lucena, C. J. P. (2007). The 3c collaboration model. In The Encyclopedia of E-Collaboration , p. 637-644.

Guerrero, L. A. and Fuller, D. A. (2001). A pattern system for the development of colla- borative applications. Information and Software Technology , 43(7), $457-467$.

Johnson, D., Johnson, R., Smith, K., and on Higher Education, E. C. (1996). Academic controversy: enriching college instruction through intellectual conflict. ERIC digest. Graduate School of Education and Human Development, George Washington University.

Menezes, C. S. d., Nevado, R. N., Castro Jr, A. N., and Santos, L. N. (2008). Morfeu Multi-Organizador Flexível de espaços virtUais para apoiar a inovação pedagógica em Ead. In Anais do Simpósio Brasileiro de Informática na Educação, volume 1, p. 451-460

Nevado, R. A., Carvalho, M. J. S., Menezes, C. S. (2007). Arquiteturas pedagógicas para educação a distância. In Aprendizagem em rede na educação a distância: estudos e recursos para formação de professores.

Nevado, R. N., Menezes, C. S. d., Vieira Junior, R. R. M. (2011). Debate de teses- uma arquitetura pedagógica. In Anais do Simpósio Brasileiro de Informática na Educação, p. 820-829.

Ochoa, S., Guerrero, L., Pino, J. A., and Collazos, C. A. (2004). Reusing groupware applications. In Groupware: Design, Implementation, and Use, p. 262-270. Springer Berlin Heidelberg,

Santos, L. N., Castro, A., and Menezes, C. S. (2010). Morfeu: Criando ambientes virtuais flexíveis na web para mediar a colaboração. In Anais do Congreso Iberoamericano de Informática Educativa , p. 114-121

Schmidt, K. and Bannon, L. (1992). Taking cscw seriously: Supporting articulation work. Computer Supported Cooperative Work (CSCW). An International Journal , p. 7- 40.

Schmitt, M. A. R. (2006), Dificuldades apresentadas pelo modelo wiki para a implementação de um ambiente colaborativo de aprendizagem. Renote, 4(2), 1-7.

Vieira Junior, R. R. M., Santos, O. L., Rafalski, J. P., Bada, E. M., Silva, H. F. A., and Menezes, C. S. (2011). Coordenação nas atividades colaborativas em ambientes de aprendizagem - uma avaliação na implementação de arquiteturas pedagógicas. Revista Renote. Vol. 9 